\title{
CORRESPONDENCE
}

\section{Lung Transplantation in Germany Since the Introduction of the Lung Allocation Score}

\author{
A Retrospective Analysis
}

by Prof. Dr. med. Jens Gottlieb; Jacqueline Smits, MD, PhD; PD Dr. med. Rene Schramm; PD Dr. med. Frank Langer; Prof. Dr. med. Roland Buhl; Prof. Dr. med. Christian Witt; Prof. Dr. med. Martin Strueber; and Prof. Dr. med. Hermann Reichenspurner in issue 11/2017

\section{Imitation is the Sincerest Form of Flattery}

Gottlieb et al. reported encouraging results after three years' use of the Lung Allocation Score (LAS) in Germany (1). I congratulate the German lung transplant community for embracing a radically different organ allocation system to provide some objectivity to lung allocation when numbers are inadequate to meet the need. For six years, I chaired the subcommittee that, with help from many people, developed the LAS for the US Organ Procurement and Transplant Network (OPTN). Until recently, LAS was the only US organ allocation system that considered post-transplant survival. I am excited that Eurotransplant uses the LAS to distribute donor lungs (2). Gottlieb reports that in Germany, the LAS was associated with more lung transplants performed (without concomitant increase in donors), a significant reduction in waitlist deaths, with no increase in post-transplant mortality, and improved distribution of recipient diagnoses. This is similar to the impact in the US (3). LAS adoption appears to have been less contentious in Germany than in the US Now Germany has enough data to make its LAS a German entity, instead of relying on old US waitlist and transplant data like us (4). Our Subcommittee intended to use new data to re-analyze risks of waitlist death and post-transplant survival every six months, and modify variable coefficients that factored into LAS calculation. Variables could be eliminated or added as the population of waitlisted patients changed, to keep the model current. Sadly, the OPTN took years to make substantive changes. The Deutsche Stiftung Organtransplantation may be more nimble. D0l: 10.3238/arztebl.2017.0543a

\section{REFERENCES}

1. Gottlieb J, Smits J, Schramm R, et al.: Lung transplantation in Germany since the introduction of the Lung Allocation Scorea retrospective analysis. Dtsch Arztebl Int 2017; 114: 179-85.

2. Eurotransplant: Introduction of the LAS in the Netherlands. 2014. www.eurotransplant.org/cms/index.php?page=newsitems \&oid=458\&action=viewitem\&id=4505 (last accessed on 23 May 2017).

3. Egan TM, Edwards LB: Effect of the lung allocation score on lung transplantation in the United States. J Heart Lung Transplant 2016; 35: 433-9

4. Egan TM, Murray S, Bustami RT: Development of the new lung allocation system in the United States. Am J Transplant 2006; 6: 1212-27.
Acknowledgement

I gratefully acknowledge the help of Prof. Frank Detterbeck, MD, Thoracic Surgery at Yale University, and Margaret Cloud.

Thomas M. Egan, M.D., M.Sc.

University of North Carolina at Chapel Hill

thomas_egan@med.unc.edu

\section{In Reply:}

We thank Dr. Egan for his interest in our publication (1) and for his endorsement of the German experience with the Lung Allocation Score (LAS). He pioneered the important concept of transplant benefit in donor lung allocation within the US, balancing the patient mortality risk after transplantation against that of remaining on the wait list. Translating this into clinical practice required great courage in 2005 , given the fundamental shift needed to prioritize outcome benefit rather than current clinical need. The results remain unequivocal, demonstrating improved wait list mortality and transplant outcomes subsequently in the US (2).

Germany adopted the LAS in 2011, with the Netherlands following in 2014, primarily for national allocation in contrast to the primarily local allocation in the US. From the outset both countries have introduced special business rules, adapted to the needs specific to the European population. One of the reasons was that the LAS does not factor in the need for extracorporeal life support (ECLS). In the 5 years that the LAS has been in operation in Germany, more than a dozen special rules have been designed and introduced to provide clarity to physicians and allow parity among candidates.

On February $19^{\text {th }}, 2015$ the US adopted a modified LAS, entailing adjustments in of some existing coefficients, alongside introducing new parameters such as cardiac index, bilirubin and creatinine. The European countries await with anticipation the upcoming publications outlining experience and the impact of these amendments.

We agree wholeheartedly with Dr. Egan that the European model needs to be kept current by analyzing waitlist outcomes and survival after transplantation in Europe as well as additional parameters continuously. We firmly believe that data quality is of extreme importance to avoid "garbage in, garbage out" in statistical modeling (3). Eurotransplant has introduced practical business rules for oxygen titration to minimize this problem and national audits in Germany have improved data quality since their introduction in 2014.

DOl: 10.3238/arztebl.2017.0543b

\section{REFERENCES}

1. Gottlieb J, Smits J, Schramm R, et al.: Lung transplantation in Germany since the introduction of the Lung Allocation Scorea retrospective analysis. Dtsch Arztebl Int 2017; 114: 179-85. 
2. Egan TM, Edwards LB: Effect of the lung allocation score on lung transplantation in the United States. J Heart Lung Transplant. 2016; 35: 433-9.

3. N.N.: Work with new electronic 'brains' opens field for army math experts. The Hammond Times 1957; 65 (retrieved on 20 March 2016 via Newspapers.com).

On behalf of the authors

Prof. Dr. med. Jens Gottlieb

Medizinische Hochschule Hannover, Biomedical Research in Endstage

and Obstructive Lung Disease Hannover (BREATH), Mitglied des Deutschen

Forschungszentrums für Lungenforschung

Gottlieb.Jens@mh-hannover.de

Jacqueline Smits, MD, PhD

Eurotransplant International Foundation, Leiden, Niederlande

Conflict of interest statement

The authors of both contributions declare that no conflict of interest exists.

\section{CLINICAL SNAPSHOT}

\section{A 76-Year-Old Woman With Chest Pain and Tarry Stool}

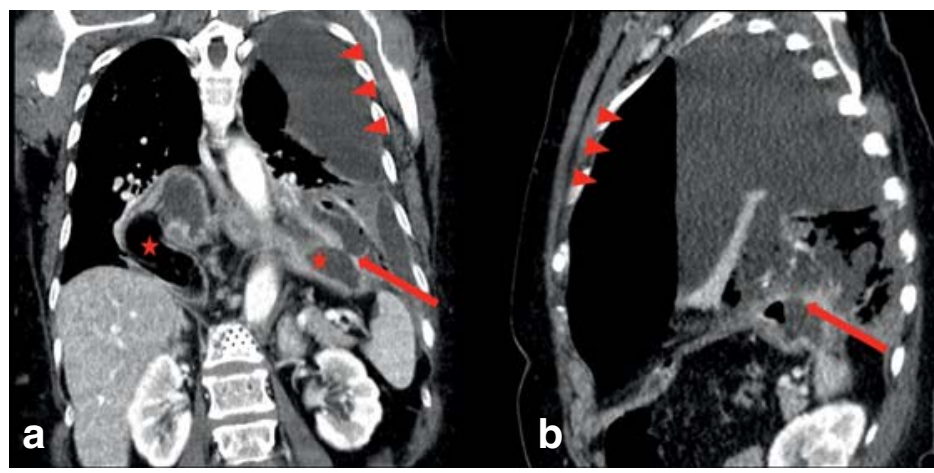

Computerized tomography on admission $(a+b)$ reveals the perforation (arrow) of the intrathoracic stomach (asterisk) into the pleural cavity. An extensive seropneumothorax is seen (triangles).
A 76-year-old woman was taken to the emergency room because of chest pain and tarry stool. She stated that she frequently used a combined preparation containing acetylsalicylic acid, acetaminophen, and caffeine.

Esophagogastroduodenoscopy was performed because of the suspected diagnosis of upper gastrointestinal bleeding. This revealed a paraesophageal hernia and an ulcer with covered perforation in the area of the gastric cardia and fundus. Computerized tomography (CT) of the chest and abdomen yielded the diagnosis of an intrathoracic stomach with perforation into the left pleural cavity (Figure). In an emergency procedure, the proximal portion of the stomach and the neighboring distal portion of the esophagus were resected, with ensuing gastric reconstruction, esophagogastrostomy, and hiatoplasty. Pleural empyema arose as a postoperative complication and was treated with irrigation and partial pleurectomy. A persistent pleural fluid collection was drained under CT guidance. The patient was discharged in stable condition after three weeks in the hospital.

Dr. med. Lars-Arne Schaafs, PD Dr. med. Zarko Grozdanovic, Klinik und Hochschulambulanz für Radiologie, Campus Benjamin Franklin, Charité-Universitätsmedizin Berlin, lars-arne.schaafs@charite.de

\section{Conflict of interest statement}

The authors state that they have no conflict of interest.

\section{Cite this as:}

Schaafs L-A, Grozdanovic Z: A 76-year old woman with chest pain and tarry stool. Dtsch Arztebl Int 2017; 114: 544. D0I: 10.3238/arztebl.2017.0544 